\title{
Emotional Intelligence and Stability in the Corona Pandemic
}

\section{Abdel-Fattah HMM*}

Neuropsychiatry Specialist, Abbassia Psychiatric Hospital, Cairo, Egypt

*Corresponding author: Abdel-Fattah HMM, Neuropsychiatry Specialist, Abbassia Psychiatric Hospital, Cairo, Egypt, Email: hesham.maged2011@yahoo.com

\section{Review Article}

Volume 4 Issue 1

Received Date: April 08, 2020

Published Date: June 11, 2020

DOI: $10.23880 / \mathrm{mhrij}-16000139$

\section{Abstract}

Two cases of gender dysphoria are presented in this article, a mother and her son who had requested legal permission for sex reassignment surgery. The cases were a 16-year-old boy and her 38-year-old biological mother who were referred to the department of forensic psychiatry in Legal Medicine Organization of Iran. They were referred to special clinics for psychiatric evaluations and finally the diagnosis "gender dysphoria" was confirmed. They were not met any criteria for other mental disorders and had not any physical abnormality. Their sex chromosomes were consistent with their physical identities. The results support the possibility of familial aggregation or a shared state of gender identity problems because of a pathologic impressibility and imitation and/or a genetic predisposition of gender dysphoria.

Keywords: Gender Dysphoria; Sex Reassignment; Shared Identity Problem; Genetic Predisposition

Abbreviations: EI: Emotional Intelligence; ES: Emotional Stability; COVID-19: Corona Virus Disease 2019.

\section{Introduction}

In light of the sudden and global spread of a catastrophe like the Corona virus (COVID-19) which affected millions of lives worldwide, not only physically but also emotionally in the form of panic attacks, obsessional behavior, anxiety, and fear. Misbehaviors have been appeared such as selfishness and storing goods which affected social cohesion and national income.

Through our duty in the field of psychiatry towards humanity, we bear a great responsibility on us to confront such crises, in which we wish to help the largest number of people at the world level. At this time, inaccurate information is a serious danger, whether in the psychological aspect or the organic side, and a lot of people around the world have their medical information through social media and not the approved medical sites. Therefore, it is necessary to differentiate between health information and rumors as well. Also, it is important to clarify the concept and acquisition of emotional intelligence and emotional stability in the face of crises.

\section{Discussion}

Emotional Intelligence significant is successfully in dealing with daily environmental pressure: selfawareness, emotional control, relationships, and effective communication.

\section{There are five components of EI}

i. Intrapersonal components include emotional selfawareness, assertiveness, self-regard, self-actualization, and independence. Similarly,

ii. Interpersonal components include empathy, social responsibility and interpersonal relationships. In addition, adaptability is highlighted by problem solving, reality testing and flexibility; and stress management can be described by stress tolerance and impulse control [1].

\section{Emotional Intelligence Affects Decision-Making}

High emotional intelligence improves decisionmaking abilities. Those who have a good understanding of 
themselves and those around them are more likely to be efficient decision making.

\section{Communication and Emotional Intelligence}

Emotional intelligence is closely related to communication skills; people with high EI tend to be efficient in their communication skills.

\section{Resilience with Emotional Intelligence}

People who are high in EI are generally able to pick themselves up when they fall as we now in pandemic crisis as corona virus. so emotional intelligence is directly related to resilience and, through that connection, it's related to achievement and achievement motivation.

\section{Concept of Emotional Stability (ES)}

Emotional stability is the ability to maintain one's emotional balance under stressful circumstances or pandemic crisis.

Emotionally stable persons can tolerate minor and major stresses and strains of day to day living without becoming upset, anxious, nervous, tense, or angry. Thus, person able to maintain composure under emotional stress. They are fairly constant in their basic mood, and revert quickly following those occasions when they have experienced highly risk stress or have been exceptionally provoked.

Emotional stability enables the person to integrated and balanced the problems of life. This organizational ability and structured perception help one to develop reality-oriented thinking, fair judgment and good evaluation ability.

\section{Are Emotionally Intelligent People More Emotionally Stable?}

The answer was yes, it's was positively relation between positive mood with high arousal and a negative mood with low arousal. In addition, a negative relationship between EI and the ES of tension and fear, anxiety was found [2].

\section{Emotional Intelligence and Stability in the Face of COVID-19}

COVID-19 is an infectious condition, which means it can be spread, directly or indirectly, from one person to another. It is caused by the newly discovered coronavirus, called as novel coronavirus, first identified in Wuhan, China, in December 2019. The lack of verified facts and floating rumors are to be blamed for the so much panic in crisis people's vulnerable to physically and psychologically negative impacts. It has been estimated that up to $80 \%$ of those affected by a crisis will have mild distress, $20-40 \%$ a psychological disorder in the medium term, and up to $5 \%$ may be left with a long-term problem [3].

Lake of information about this virus no one can knows what lasting effect on the economy, whether it will subside or keep spreading and be pandemic in more areas. This crisis is testing everyone's emotional intelligence and emotional stability. Those who survive are not the strongest or the most intelligent, but the most adaptable to change. It's the responsibility of leaders to show empathy, optimism, and flexibility that will lead the people out of this

\section{People Who May Respond Strongly to the Stress of this Pandemic Crisis Include}

- Older people and people with chronic diseases who had poor immunity.

- Children and teens.

- People who are working in the medical field, like doctors and nurses and other health care providers.

- People who have mental health conditions like substance use disorders.

\section{Worming Signs of Stress During a Pandemic Crisis Can Include}

I. Fear and worry about one's health and the health of his loved people.

II. Decreased in working capacity.

III. Changes in eating patterns.

IV. Difficult in sleeping and concentrating.

V. decaling in chronic health diseases.

VI. Increasing of usage of alcohol, tobacco, or other drugs.

\section{How to Reduce Stress in Crises}

Sharing the official and accurate facts about COVID-19 and understanding the risk to oneself and people can make an outbreak less stressful.

parents and caregivers deal with the COVID-19 calmly and confidently, they provide the best support for their children. Parents can be more reassuring to their children, if they are better prepared.

\section{There are Many Things Could be Done to Support a Child}

I. Giving enough time to talk with the child about the COVID-19 simply answering questions and sharing facts 


\section{Mental Health \& Human Resilience International Journal}

in a way they can understand.

II. Reassuring them that they are safe. Letting them know it is ok if they feel anxious teaching him how can be a deal with their own stress so that they can cope.

III. Deceasing family's exposure to news coverage of the crisis, including social media. Children may misinterpret what they hear and becoming frightened about something they do not understand.

IV. Keeping up with protective measures from infections. If schools are closed, training to create a schedule for learning and funny activities.

V. Parents must be role models; take breaks, get sufficient of sleep, exercise, and eating well, and connect with their friends and family through chats and multimedia coverage.

\section{Recommendations}

There are certain ways to ease the Coronavirus anxiety:

1. Searching and learning: Having recommended trustful knowledge has been shown to be a strong protective factor.

2. Identifying the source of anxiety: knowing your felling as a part of EI can be eradicate the source of anxiety.

3. Accepting: emotional like anxiety, fear, anger or frustration is absolutely normal and is a good sign that our body's trying to protective us.

4. Considering the received information: we may find it useful to restrict our input to sources of information or consciously seek out information only from trusted sources.

5. Taking self-care: we can learn ways to calm ourselves down and fulfilling our time with useful projects.
6. Practicing self-compassion: don't be hard on yourself as fear is a normal human emotion to protect us.

7. Thinking about the effects on others: consider how others are feeling about this threat at the moment. This might be those who are currently suffering.

8. Asking for help don't afforded from asking medical or psychological helping when you need it.

9. Connecting and connecting: It's essential to stay in communication with your family, friends, neighbors and other resources by media.

10. Avoiding shaming and blaming: do best of your efforts by follow up the official instructions from your government.

11. Focusing on what could be controlled: writing all your emotion's what can control it and what cannot? and sharing it with loved ones.

12. Thinking in prevention not avoidance: engage in productive health behaviors (recommended preventive behavior) that much better to avoiding people and places.

13. Focusing on the present moment: focus on what is happening right here and right now.

14. Preparing for the worst: precautionary measures must be done and making a brain storming in the futures to making alternative plans if its worst.

15. Preventing anxiety to be pandemic too: we should believe in our capability that's we will win the war with this pandemic corona virus and we will be living our life save and happy.

\section{Reference}

1. Stein S, Book H (2002) The EQ Edge: Emotional Intelligence and Your Success. 